JGG 2021;69:265-268

doi: $10.36150 / 2499-6564-N 456$
Clinical Geriatrics - Reviews

\section{Osteoporosis/bone fragility}

\author{
Nicola Napoli, Flavia Tramontana
}

Department of Endocrinology and Diabetology, Campus Bio-Medico University, Rome, Italy; Italian

Society of Gerontology and Geriatrics, Florence, Italy; Italian Society of Diabetology, Rome, Italy
Received: July 30, 2021

Accepted: September 16, 2021

\section{Correspondence}

Nicola Napoli

Department of Endocrinology and Diabetology,

Campus Bio-Medico University, via Alvaro del

Portillo 21, 00128 Rome, Italy

E-mail: n.napoli@unicampus.it

How to cite this article: Napoli N, Tramontana F. Osteoporosis/bone fragility. Journal of Gerontology and Geriatrics 2021;69:265-268. https://doi. org/10.36150/2499-6564-N456

(C) Copyright by Società Italiana

di Gerontologia e Geriatria (SIGG)

\section{(c) (1) () $(9$}

This is an open access article distributed in accordance with the CC-BY-NC-ND (Creative Commons Attribution-NonCommercial-NoDerivatives 4.0 International) license. The article can be used by giving appropriate credit and mentioning the license, but only for non-commercial purposes and only in the original version. For further information: https://creativecommons.org/licenses/by-nc-nd/4.0/deed.en

\section{RECOMMENDATIONS}

A. In elderly subjects with T2DM, the identification and management of diabetic patients with increased fracture risk should follow the algorithm proposed by the International Osteoporosis Foundation (IOF), as shown in Figure 1 (grade: $1 A)^{1}$. All of these patients should undergo a dual-energy $x$-ray absorptiometry (DXA) scan to measure bone mineral density. A DXA scan is also indicated for individuals older than 50 years and/or individuals with a previous fragility fracture or treated with thiazolidinediones. The 2020 American Diabetes Association (ADA) standards of care recognize that the risk of fracture is significantly higher in individuals with DM, for both genders and all age groups, and recommend assessing fracture history and risk factors for fracture, especially in elderly DM patients ${ }^{2}$. DXA-derived t-scores should be corrected by a factor of 0.5 in DM patients (e.g., t-score $<-2.0$ in a patient with DM is equivalent to $<-2.5$ in a non-diabetic patient) (grade: $2 A)^{3}$.

B. Regardless of DXA parameters, it is important to assess fracture risk with patient interview and the Fracture Risk Assessment Tool (FRAX $\left.{ }^{\circledR}\right)$ during screening visits, especially for patients with a long diabetes duration. When using FRAX ${ }^{\circledR}$ in the assessment of DM patients, the rheumatoid arthritis option should be checked (grade: $2 A)^{1,4}$. If results are above the suggested cutoffs, the patient should be monitored with repeated DXA and FRAX ${ }^{\circledR}$ assessments at regular intervals of 2-3 years ${ }^{1}$.

C. Patients with a T-score $<-2.0$, or above the FRAX algorithm's treatment threshold, should be started on anti-resorptive therapy. Drugs of first choice are bisphosphonates (alendronate or risedronate) (grade: 2A) ${ }^{5,6}$. Although there is less evidence about denosumab, it remains a valid choice for patients who cannot tolerate bisphosphonates or have chronic kidney disease.

D. It is also recommended that vitamin $D$ deficiency be prevented by providing the recommended daily intakes of $800 \mathrm{IU}$ per day for elderly patients or, in vitamin $D$ deficiency, by providing higher doses without exceeding the maximum tolerability dose of $4000 \mathrm{IU}$ per day (grade: $4 A)^{7}$. Vitamin D supplementation strategies should aim at the optimal serum concentration of $25(\mathrm{OH}) \mathrm{D}$ in frail geriatric patients, i.e., $>30 \mathrm{ng} / \mathrm{ml}$.

\section{STRENGTH OF THE RECOMMENDATIONS}

The quality of the evidence is moderate and supported by published evidence. 


\section{SUPPORTING EVIDENCE}

See appendix.

\section{AREAS OF UNCERTAINTY AND FUTURE PERSPECTIVES}

The clinical management of patients with diabetic bone fragility is complex and still suboptimal. Interpretation of the clinical significance of BMD is difficult, but BMD should be assessed on a regular basis to monitor bone loss. Evidence supporting the use of anti-osteoporotic treatment in DM patients is relatively scarce, but treatment should not be neglected. Romosozumab, a novel bone anabolic agent, is a promising option that needs to be tested in future studies. The effect of vitamin D on muscle health and falls prevention remains controversial.

\section{APPENDIX}

DM and osteoporosis are two chronic diseases with a high prevalence, especially in the geriatric population. These two conditions often coexist and are characterized by changes in mineral density, growth, and bone remodeling, as well as by an increased fracture risk. There is increasing evidence that bone fragility should be included among diabetes complications ${ }^{8}$.

Diabetes mellitus has a higher prevalence in persons aged 70-79 years ${ }^{9}$, an age group where a significant proportion of individuals also have osteoporosis. It is estimated that osteoporosis affected 22 million women and 5.5 million men in the European Union in $2010^{10}$. In older persons, especially those with DM, other factors contribute exponentially to fracture risk, such as changes in bone quality, diabetic complications (e.g., diabetic retinopathy and/or diabetic nephropathy), drug therapies, immobility, frailty, and comorbid conditions that increase the risk of falls ${ }^{11}$.

Different mechanisms contribute to changes in bone health in DM. Non-enzymatic glycation of type I collagen, low bone turnover, chronic low-grade inflammation, and microvascular alterations are all factors leading to abnormalities in bone micro- and macro-architecture that underpin reduced resistance to mechanical stress ${ }^{8}$. Bone structural changes in T2DM include increased cortical porosity and reduced cortical thickness. Studies have shown different patterns of bone mineral density in DM, which is generally reduced in T1DM and normal or increased in T2DM. In T2DM patients, bone mineral density is $5-10 \%$ higher than in persons without $\mathrm{DM}^{12}$. However, despite high bone mineral density, several studies have shown that bone quality is compromised in T2DM patients, particularly in older people ${ }^{13}$. This explains the paradox of an increased risk of fracture associated with T2DM despite patients having high bone mineral density ${ }^{14}$. Typical diabetic complications such as diabetic neuropathy leading to poor balance, diabetic retinopathy, and impaired kidney function are all factors associated with increased risk of falls and fractures. In addition, serum markers of bone turnover are generally lower in DM patients than in normoglycemic individuals, raising concerns that anti-resorptive drugs used to treat osteoporosis may further suppress bone remodeling in patients with DM. Although the evidence is limited, data from clinical trials suggest that osteoporosis drugs are effective in DM patients.

Bisphosphonates are potent anti-resorptive medications and their effectiveness in preventing fractures has been widely demonstrated in clinical trials. Among the few available data in diabetic patients, a post-hoc analysis from the FIT trial showed that 3 years of treatment with alendronate increased bone mineral density to levels similar to non-diabetic individuals ${ }^{15}$. These findings are limited to BMD and in a subgroup of 297 DM patients without information on fracture risk. Even less evidence is available for denosumab, an anti-resorptive agent that targets the RANKL, inhibiting osteoclast activation. A post-hoc analysis of the FREEDOM trial has proved that denosumab significantly increased $\mathrm{BMD}$ and lowered vertebral fracture risk, while no effect was observed on non-vertebral fractures (Ferrari, Bone 2020). A favorable effect in DM patients has also been observed with teriparatide, an anabolic agent that increases both bone formation and, to a lesser extent, bone resorption. Teriparatide could therefore play a particularly positive role in the prevention of bone fragility in $\mathrm{DM}$, which is characterized by reduced bone remodeling. An analysis of four observational studies including more than 8,800 patients treated with teriparatide (20 $\mu \mathrm{g}$ per day for up to 24 months) showed a significant reduction in all fracture types after six months of treatment, with higher efficacy in DM than non-diabetic individuals ${ }^{16}$.

On the other hand, different drugs used to treat DM can affect bone health. Indeed, insulin treatment is another risk factor for falls and fractures, probably due to an increase in hypoglycemic events. The adverse effects of thiazolidinediones on bone health are well known. These drugs are not recommended in post-menopausal women or in elderly men ${ }^{17,19}$. SGLT2-inobitors such as canagliflozin, which was shown to increase the risk of fractures in the CANVAS study, should be used with caution in the elderly. However, this finding was not confirmed in other randomized studies ${ }^{2,18-21}$. Particular care should also be taken with drugs that can cause 
hypoglycemia, such as insulin, sulfonylureas, or glinides (grade: $3 A)^{2}$.

Finally, DM patients, especially if elderly, exhibit higher rates of hypovitaminosis $D$ than non-diabetic patients ${ }^{22}$. Vitamin $D$ plays a central role in maintaining bone health and in reducing the risk of falls ${ }^{23}$, and maintaining adequate vitamin $\mathrm{D}$ levels is recommended during treatment with anti-osteoporotic drugs to support their efficacy. Vitamin D status should be monitored over time in patients with high risk of hypovitaminosis- $D$, measuring serum concentration of 25-hydroxyvitamin D (25OHD). More importantly, it is crucial that all elderly DM patients achieve an intake of at least $800 \mathrm{UI}$ of vitamin D per day, which can be increased up to $4000 \mathrm{UI}$ according to specific needs.

\section{Ethical consideration}

None.

\section{Acknowledgement}

None.

\section{Funding}

None.

\section{Conflict of interest}

The Authors declare no conflict of interest.

\section{References}

1 Ferrari SL, Abrahamsen B, Napoli N, et al. Diagnosis and management of bone fragility in diabetes: an emerging challenge. Osteoporos Int 2018;29:2585-2596. https:// doi.org/10.1007/s00198-018-4650-2

2 American Diabetes Association. Standards of medical care in diabetes, 2020. Diabetes Care 2020;43(Suppl 1):S37S47. https://doi.org/10.2337/dc20-S004

3 Schwartz AV, Vittinghoff E, Bauer DC, et al. Association of BMD and FRAX score with risk of fracture in older adults with type 2 diabetes. JAMA 2011;305:2184-2192. https:// doi.org/10.1001/jama.2011.715

4 Leslie WD, Lix LM, Langsetmo L, et al. Construction of a FRAX ${ }^{\circledR}$ model for the assessment of fracture probability in Canada and implications for treatment. Osteoporos Int 2011;22:817-827. https://doi.org/10.1007/ s00198-010-1464-2

5 Cosman F, de Beur SJ, LeBoff MS, et al. Clinician's Guide to prevention and treatment of osteoporosis. Osteoporos Int 2014;25:2359-2381. https://doi.org/10.1007/ s00198-014-2794-2

6 Shoback D, Rosen CJ, Black DM, et al. Pharmacological management of osteoporosis in postmenopausal women: an Endocrine Society Guideline Update. J Clin Endocrinol Metab 2020;105:dgaa048. https://doi.org/10.1210/ clinem/dgaa048
7 Ross AC, Taylor CL, Yaktine AL, et al. Dietary reference intakes for calcium and vitamin D. Washington (DC): National Academies Press (US) 2011. https://doi. org/10.17226/13050

8 Napoli N, Chandran M, Pierroz DD, et al. Mechanisms of diabetes mellitus-induced bone fragility. Nat Rev Endocrinol 2017;13:208-219. https://doi.org/10.1038/ nrendo.2016.153

9 International Diabetes Federation. IDF Diabetes Atlas, $9^{\text {th }}$ ed. 2019. ISBN: 978-2-930229-87-4. https://www.diabetesatlas.org/upload/resources/material/20200302_133351_ IDFATLAS9e-final-web.pdf

10 Hernlund E, Svedbom A, Ivergård M, et al. Osteoporosis in the European Union: medical management, epidemiology and economic burden. A report prepared in collaboration with the International Osteoporosis Foundation (IOF) and the European Federation of Pharmaceutical Industry Associations (EFPIA). Arch Osteoporos 2013;8:136. https:// doi.org/10.1007/s11657-013-0136-1

11 Rossini M, Adami S, Bertoldo F, et al. Linee guida per la diagnosi, la prevenzione ed il trattamento dell'osteoporosi. Reumatismo 2016;68:1-42.

12 Bonds DE, Larson JC, Schwartz AV, et al. Risk of fracture in women with type 2 diabetes: the Women's Health Initiative Observational Study. J Clin Endocrinol Metab 2006;91:3404-3410. https://doi.org/10.1210/ jc.2006-0614

13 Petit MA, Paudel ML, Taylor BC, et al. Bone mass and strength in older men with type 2 diabetes: the Osteoporotic Fractures in Men Study. J Bone Miner Res 2010;25:285291. https://doi.org/10.1359/jbmr.090725

14 Napoli N, Strotmeyer ES, Ensrud KE, et al. Fracture risk in diabetic elderly men: the MrOS study. Diabetologia 2014;57:2057-2065. https://doi.org/10.1007/ s00125-014-3289-6

15 Keegan THM, Schwartz AV, Bauer DC, et al. Effect of alendronate on bone mineral density and biochemical markers of bone turnover in type 2 diabetic women: the fracture intervention trial. Diabetes Care 2004;27:1547-1553. https://doi.org/10.2337/diacare.27.7.1547

16 Langdahl BL, Silverman S, Fujiwara S, et al. Real-world effectiveness of teriparatide on fracture reduction in patients with osteoporosis and comorbidities or risk factors for fractures: integrated analysis of 4 prospective observational studies. Bone 2018;116:58-66. https://doi.org/10.1016/j. bone.2018.07.013

17 Palermo A, D'Onofrio L, Eastell R, et al. Oral anti-diabetic drugs and fracture risk, cut to the bone: safe or dangerous? A narrative review. Osteoporos Int 2015;26:20732089. https://doi.org/10.1007/s00198-015-3123-0

18 Watts NB, Bilezikian JP, Usiskin K, et al. Effects of canagliflozin on fracture risk in patients with type 2 diabetes mellitus. J Clin Endocrinol Metab 2016;101:157-166. https:// doi.org/10.1210/jc.2015-3167 
19 Taylor SI, Blau JE, Rother KI. Possible adverse effects of SGLT2 inhibitors on bone. Lancet Diabetes Endocrinol 2015;3:8-10. https://doi.org/10.1016/ s2213-8587(14)70227-x

20 Zhou Z, Jardine M, Perkovic V, et al. Canagliflozin and fracture risk in individuals with type 2 diabetes: results from the CANVAS Program. Diabetologia 2019;62:1854-1867. https://doi.org/10.1007/s00125-019-4955-5

21 Perkovic V, Jardine MJ, Neal B, et al. Canagliflozin and renal outcomes in type 2 diabetes and nephropathy. $\mathrm{N}$ Engl J Med 2019;380:2295-2306. https://doi.org/10.1056/ nejmoa1811744
22 Isaia G, Giorgino R, Adami S. High prevalence of hypovitaminosis $D$ in female type 2 diabetic population. Diabetes Care 2001;24:1496. https://doi.org/10.2337/ diacare.24.8.1496

23 Bischoff-Ferrari HA, Dawson-Hughes B, Staehelin HB, et al. Fall prevention with supplemental and active forms of vitamin D: a meta-analysis of randomised controlled trials. BMJ 2009;339:b3692. https://doi.org/10.1136/bmj. b3692

\section{This statement is:}

Recommendation (supported by published evidence)

$\triangle$ Best practice (supported by expert opinion)

\section{Quality of the evidence (in the case of recommendation):}

$\square$ Low

Мoderate

High 